\title{
Aplicação de uma sequência didática elaborada com base na tecnologia de realidade aumentada
}

\author{
Renato Oliveira Abreu ${ }^{1}$, Paulo Henrique de Souza ${ }^{1}$ \\ ${ }^{1}$ Instituto Federal de Educação, Ciência e Tecnologia de Goiás - Câmpus Jataí \\ 75.800-000 - Jataí - GO - Brasil \\ \{renato.abreu.info, phsouzas\}@gmail.com
}

\begin{abstract}
The use of the augmented reality in the educational environment has been increasing the each year, this proposal enables the application of computational resources to teaching content through images, videos and three-dimensional objects. In this work we elaborated a didactic sequence in order to evaluate the contribution of augmented reality to the learning process. A didactic material, and a software, with augmented reality was prepared by associating videos and three-dimensional objects to the study of the Solar System. After the implementation of the proposal we noted a satisfactory involvement of students in the activities and greater motivation for studying the content.
\end{abstract}

Resumo. A utilização da realidade aumentada no meio educacional vem aumentando a cada ano, esta proposta possibilita a aplicação de recursos computacionais ao ensino de conteúdos por meio de imagens, vídeos e objetos tridimensionais. Neste trabalho elaboramos uma sequência didática com a finalidade de avaliarmos a contribuição da realidade aumentada para o processo de aprendizagem. Um material didático, e um software, com realidade aumentada foi elaborado associando vídeos e objetos em três dimensões para o estudo do Sistema Solar. Após a aplicação da proposta observamos um satisfatório envolvimento dos alunos nas atividades e uma maior motivação para o estudo do conteúdo.

\section{Introdução}

O desenvolvimento científico e tecnológico traz implicações profundas para o modo de vida dos indivíduos, a informática destaca-se por se fazer presente e influenciar na dinamização das atividades de um número cada vez maior de setores da sociedade.

Segundo Moran (2006) a integração de tecnologias, metodologias e atividades, com inserção do universo audiovisual é considerada um dos princípios norteadores metodológicos que podem auxiliar o trabalho dos educadores. $\mathrm{O}$ autor propõe a integração de tecnologias, telemáticas, audiovisuais, textuais, orais, musicais, lúdicas, corporais para favorecer a aprendizagem, ressaltando que o professor precisa encontrar a forma mais adequada de integrar a tecnologia com as opções metodológicas, diante de tantas possibilidades existentes, e ainda enfatiza o uso da linguagem audiovisual, inserção da televisão e do vídeo na educação escolar, porque desenvolve múltiplas atitudes perceptivas. 
V Congresso Brasileiro de Informática na Educação (CBIE 2016)

Anais do XXVII Simpósio Brasileiro de Informática na Educação (SBIE 2016)

No software desenvolvido neste trabalho utilizamos a tecnologia de Realidade Aumentada para exibição de vídeos informativos e objetos virtuais em três dimensões, essa tecnologia pode ser valiosa na área de educação, pois, conforme Souza e Kirner (2011),

a experiência educacional oferecida por ela é diferente das demais tecnologias, porque ela permite uma interação transparente entre os ambientes reais e virtuais, usa uma interface tangível para a manipulação dos objetos e permite uma transição suave entre a realidade e a virtualidade. (BILLINGHURST, 2002 apud SOUZA; KIRNER, 2011, p. 3).

A utilização dos recursos didáticos digitais deve ser planejada, podendo ainda incorporar outras metodologias de ensino. Na sequência didática proposta neste trabalho, ao final de cada aula aplicamos atividades para o desenvolvimento de atividades em grupo. Acreditamos que essa pesquisa apresenta três produtos, sendo eles, (i) a sequência didática, (ii) o material elaborado com o conteúdo das aulas e o (iii) objeto digital educacional desenvolvido.

\section{As tecnologias da informação e comunicação e suas aplicações na educação}

Estamos assistindo já há algumas décadas ao surgimento de uma nova forma de organização econômica, social, política e cultural, identificada como Sociedade da Informação (SI), que comporta novas maneiras de trabalhar, de comunicar-se, de relacionar-se, de aprender, de pensar e, em suma, de viver. (COLL e MONEREO, 2010)

Coll e Monereo (2010), elencam quatro grandes forças impulsoras que vem promovendo a rápida expansão das "sociedades virtuais" (corporações virtuais, bibliotecas virtuais, aulas virtuais), são elas: o desenvolvimento de economias globais, as políticas nacionais de apoio à internet, a crescente alfabetização digital da população e o melhoramento gradual das infraestruturas tecnológicas.

Podemos afirmar que a tecnologia está, cada vez mais, se fazendo presente em nosso quotidiano e a sua evolução é perceptível em todos os seguimentos da sociedade moderna, sendo assim, a educação não poderia deixar de valer-se dos benefícios oportunizados pela tecnologia (VIEIRA, 2006).

\subsection{Principais usos do computador na educação}

Coll e Monereo (2010) analisam a frequência e os tipos de uso das TIC pelos alunos e professores nas escolas de ensino fundamental e médio na Espanha, no que diz respeito ao equipamento e à infraestrutura, e concluem que é necessário aumentar o número de salas de aula com computadores e conexão com a internet, enquanto não houver melhoras nesse aspecto, será limitado o impacto das TIC sobre o processo de ensino e aprendizagem e sobre as práticas educacionais docente.

No mesmo trabalho, Coll e Monereo (2010) observam que os professores utilizam com mais frequência as TIC no âmbito do trabalho pessoal (busca de informação na internet, utilização do editor de textos, gerenciamento do trabalho pessoal, preparação de aulas), do que como apoio às atividades docentes em sala de aula 
V Congresso Brasileiro de Informática na Educação (CBIE 2016)

Anais do XXVII Simpósio Brasileiro de Informática na Educação (SBIE 2016)

(apresentações, simulações, utilização de software educacional) e de usos relacionados com a comunicação e trabalho colaborativo entre os alunos.

\subsection{Realidade aumentada}

Kirner e Siscoutto (2007) definem Realidade Aumentada da seguinte forma "...é um sistema que suplementa o mundo real com objetos virtuais gerados por computador, parecendo coexistir no mesmo espaço...” (KIRNER e SISCOUTTO, 2007, p. 10).

Cardoso et. al. (2014, p.332) afirma que: "esse recurso tecnológico torna-se extremamente eficiente por possuir a capacidade de exibir objetos, com uma grande riqueza de detalhes, no contexto solicitado pelo docente, sem ter que ficar imaginando tais objetos". A figura 1 ilustra bem o mecanismo de funcionamento de uma aplicação de RA. A aplicação captura a imagem por meio de uma câmera, e ao identificar o código previamente configurado (marcador), sobrepõe ao marcador, em um dispositivo de saída (monitor de vídeo, datashow), um ou mais objetos virtuais.

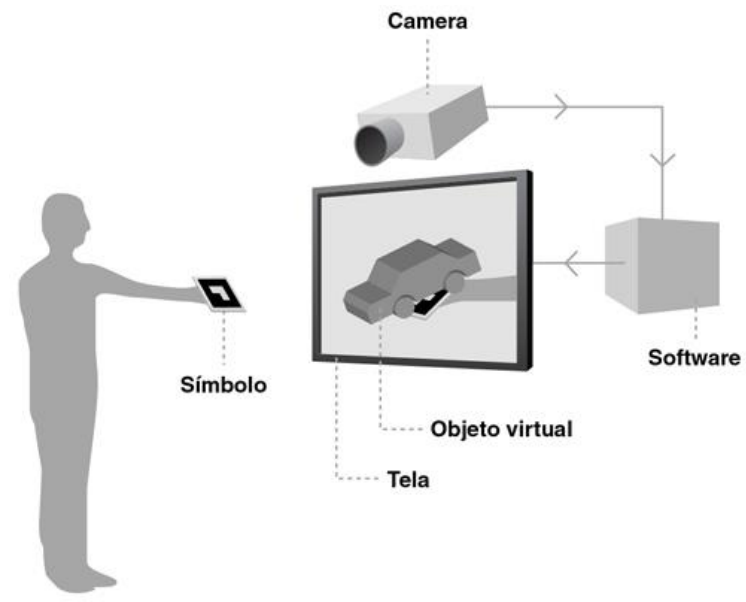

Figura 1. Exemplo de funcionamento de uma aplicação com Realidade Aumentada. Cardoso et. al. (2014)

\subsection{Realidade aumentada na educação}

Segundo Prezotto, Silva e Vanzin (2013, p.323) a RA parte de três princípios: "Combina elementos virtuais com o ambiente real, é interativa com processamento em tempo real e é concebida em três dimensões". Isso faz com que a tecnologia de RA atenda diversas áreas da sociedade moderna. Uma dessas áreas é a da educação, pois, a RA proporciona uma nova experiência ao estudante e uma interação com o ambiente sem a necessidade de treinamento, aumentando sua visão do mundo real, uma vez que ela pode inserir objetos virtuais no ambiente real.

Algumas das principais vantagens da utilização de técnicas de RA para fins educacionais é a motivação de estudantes e usuários de forma geral, baseada na experiência de primeira pessoa vivenciada pelos mesmos. A mesma permite visualizações de detalhes de objetos que estão a grandes distâncias, como um planeta ou um satélite. Também pode ser usada para experimentos virtuais, fazendo assim com que o aprendiz possa refazer experimentos de forma atemporal, fora do âmbito de uma aula clássica. (PREZOTTO, SILVA e VANZIN, 2013). 
V Congresso Brasileiro de Informática na Educação (CBIE 2016)

Anais do XXVII Simpósio Brasileiro de Informática na Educação (SBIE 2016)

\section{Percursos metodológicos}

Neste trabalho, elaboramos uma sequência didática para aplicação em três aulas de noventa minutos cada, uma vez que a instituição escolhida tem como característica aulas geminadas, ou seja, duas aulas de quarenta e cinco minutos ministradas em sequência.

\subsection{Estrutura resumida da sequência didática}

Planejamos três momentos abordando conteúdos relacionados ao Sistema Solar, nessas aulas foram usados recursos multimídia, como vídeos e imagens, além de objetos virtuais em três dimensões. Além disso, pensamos em atividades em grupo para serem desenvolvidas ao final de cada encontro, as atividades foram planejadas para que os alunos compreendessem as dimensões do Sistema Solar e o professor pudesse acompanhar o desenvolvimento do aluno a cada encontro, realizando avaliações contínuas.

Elaboramos um material de apoio pedagógico com realidade aumentada, visando possibilitar ao aluno a visualização de imagens e animações dos corpos celestes. Entendemos que a visualização dos fenômenos auxilia na compreensão dada pela comunidade científica aos modelos de criação do Universo e do Sistema Solar, o que deve também aproximar os alunos dos diferentes conhecimentos e recursos tecnológicos utilizados e elaborados nas instituições de pesquisa, muitas das quais procuram divulgar a ciência e os avanços nesta área.

Para a sequência didática, utilizada nesta proposta, nos baseamos no conceito de Zabala (1998), o qual define que,

... um conjunto de atividades, estruturadas e articuladas para a realização de certos objetivos educacionais, que têm um princípio e um fim conhecidos tanto pelos professores como pelos alunos (ZABALA, 1998, p.18).

Ainda segundo Zabala (1998) a sequência didática deve proporcionar uma visão crítica sobre sua prática educativa, na tabela 1 apresentamos a sequência que elaboramos, a qual foi aplicada pela professora de Física em três de suas aulas.

Tabela 1. Estrutura resumida da sequência didática

\begin{tabular}{|c|c|}
\hline Data & Conteúdo \\
\hline $\begin{array}{l}\text { 13/04 } \\
\text { Aula } 1\end{array}$ & $\begin{array}{l}\text { Questionário diagnóstico } \\
\text { Debate com os alunos sobre conceitos básicos de astronomia } \\
\text { •O que é o Sistema Solar? } \\
\text { •Como surgiu o Sistema Solar? } \\
\text { •Quais planetas fazem parte do Sistema Solar? } \\
\text { Trabalhar com os alunos o material didático com realidade aumentada } \\
\text { Atividade } \\
\text { Representação do sistema solar. (Atividade com desenho) }\end{array}$ \\
\hline $\begin{array}{l}27 / 04 \\
\text { Aula } 2\end{array}$ & $\begin{array}{l}\text { Debate com os alunos sobre conceitos básicos de astronomia } \\
\text { •Qual a composição física dos planetas? Como classifica-los? } \\
\text { •Você sabia que plutão não é mais considerado um planeta? }\end{array}$ \\
\hline
\end{tabular}


V Congresso Brasileiro de Informática na Educação (CBIE 2016)

Anais do XXVII Simpósio Brasileiro de Informática na Educação (SBIE 2016)

\begin{tabular}{|c|c|}
\hline & $\begin{array}{l}\text { Trabalhar com os alunos o material didático com realidade aumentada } \\
\text { Atividade } \\
\text { Representação do diâmetro dos planetas do sistema solar em proporção. } \\
\text { (Atividade com desenho) }\end{array}$ \\
\hline $\begin{array}{l}04 / 05 \\
\text { Aula } 3\end{array}$ & $\begin{array}{l}\text { Debate com os alunos sobre conceitos básico de astronomia } \\
\text { •Quais os principais tipos de movimentos do nosso planeta (Terra)? } \\
\text { •Porque acontece o dia e a noite? } \\
\text { •Como se dão as Estações do ano? } \\
\text { Trabalhar com os alunos o material didático com realidade aumentada } \\
\text { Questionário sobre a ferramenta e pós-teste } \\
\text { Atividade } \\
\text { Representação da distância entre os planetas fora da sala de aula. }\end{array}$ \\
\hline
\end{tabular}

Durante as aulas, foram utilizados recursos multimídia para projeção do material entregue aos alunos em formato de apostila. As aulas aconteceram no laboratório de informática, onde utilizamos os computadores equipados com webcam, para utilização do software desenvolvido, sendo que todos esses equipamentos já citados foram fornecidos pela instituição. Além disso, foram utilizadas cartolinas, e material de desenho, para o desenvolvimento das demais atividades.

Para a realização das atividades, propostas na sequência didática, os estudantes se organizaram em grupos, escolhidos por eles mesmos, porém, a professora solicitou que os grupos fossem mantidos até o final das aulas.

\subsection{Aplicação da sequência didática}

Nessa pesquisa utilizou-se um delineamento pré-experimental, que segundo Moreira (2011), é usado na pesquisa em ensino " $\mathrm{O}^{1} \mathrm{X} \mathrm{O}^{2}$ ", isso significa que, observa-se, o mesmo grupo antes e depois do tratamento $X$, que nessa pesquisa vem a ser a utilização de recurso didático alternativo. Neste delineamento, aplica-se um pré-teste ou teste diagnóstico $\mathrm{O}^{1}$ a um grupo, aplica-se o tratamento $\mathrm{X}$ a esse grupo e então um pós-teste $\mathrm{O}^{2}$.

Sendo assim, na primeira aula, conforme definido na sequencia didática, aplicamos inicialmente o teste diagnóstico elaborado pelo pesquisador. Na sequência a professora propiciou aos estudantes um momento de discussão, por meio de questionamentos como, o que é o Sistema Solar? Como surgiu o Sistema Solar? Quais planetas fazem parte do Sistema Solar? Em seguida foi pedido para os alunos acessassem a aplicação de realidade aumentada, porém, alguns problemas técnicos, referente a conexão dos computadores em rede, impediram o funcionamento da aplicação. A professora da disciplina seguiu o que estava definido na sequência didática e, com base nas discussões ocorridas no início da aula, pediu para que os alunos desenvolvessem a atividade proposta.

Como a aplicação da atividade com realidade aumentada, planejada para primeira aula, ficou prejudicada pela falha na rede, na segunda aula retomamos a mesma, conforme pode ser observado na figura 2 e seguiu-se o proposto na sequência. Os estudantes visualizaram as características dos planetas manuseando a aplicação 
V Congresso Brasileiro de Informática na Educação (CBIE 2016)

Anais do XXVII Simpósio Brasileiro de Informática na Educação (SBIE 2016)

desenvolvida, porém, a atividade elaborada para esse momento precisou ser desenvolvida extraclasse devendo ser entregue no próximo encontro.

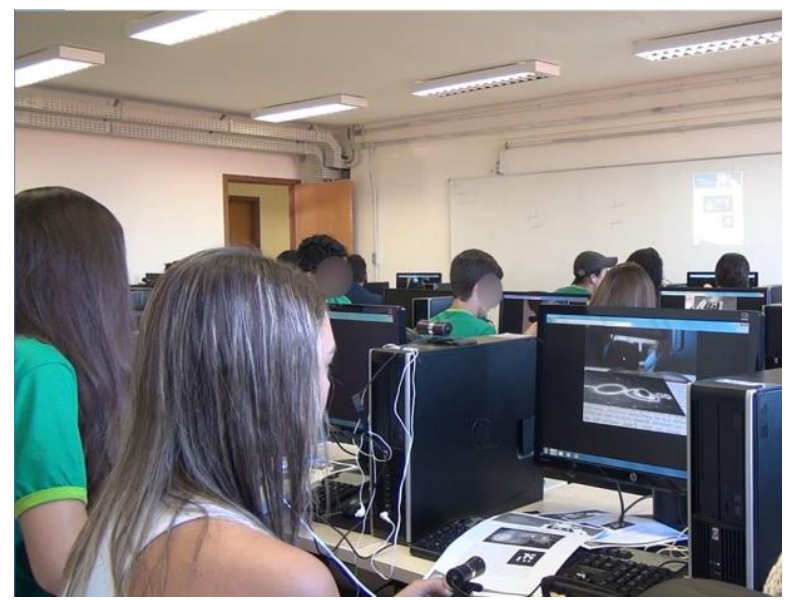

Figura 2. Estudantes manuseando a aplicação desenvolvida

No terceiro e último encontro, os estudantes tiveram acesso a mais três vídeos, que abordavam a classificação de Plutão como planeta anão, os movimentos de rotação e translação e um outro vídeo referente as estações do ano. Logo após, aplicamos o questionário que visava compreender a percepção dos estudantes sobre a tecnologia utilizada e também o questionário denominado pós-teste. Em seguida, desenvolvemos a atividade destinada a representação do sistema solar, a qual foi desenvolvida fora do ambiente da sala de aula, em grupo, onde um integrante do grupo representou o Sol e cada um dos demais membros representaram um planeta do sistema solar, ou seja, cada grupo foi composto por nove alunos. Na figura 3 mostramos os alunos reunidos em grupo momentos antes de realizar a representação do sistema solar, decidindo qual seria a unidade de medida que utilizariam.

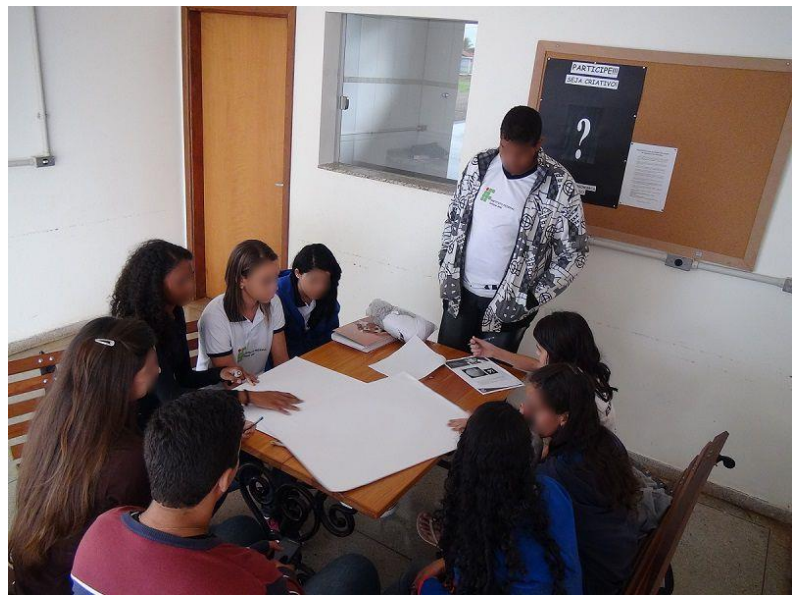

Figura 3. Estudantes desenvolvendo atividade em grupo

\section{Análise de resultados}

Segundo Bardin (2004) é necessário que os resultados brutos sejam tratados de maneira a serem significativos, ou seja, que os dados falem por si só e que sejam válidos. $\mathrm{O}$ pesquisador "tendo à sua disposição resultados significativos e fiéis, pode então propor 
V Congresso Brasileiro de Informática na Educação (CBIE 2016)

Anais do XXVII Simpósio Brasileiro de Informática na Educação (SBIE 2016)

inferências e adiantar interpretações a propósito dos objetivos previstos". (BARDIN, 2004, p. 131).

\subsection{Análise do teste diagnóstico}

Nessa pesquisa utilizamos como instrumento de coleta de dados questionários e relatórios das atividades em grupo desenvolvidas pelos estudantes. A princípio analisamos algumas das questões do instrumento que denominamos de teste diagnóstico. Uma das questões tinha como objetivo verificar se os alunos estavam atualizados sobre a retirada de Plutão como categoria de planeta que compõem o sistema solar. A maioria dos pesquisados acertaram a resposta, porém quatro estudantes marcaram a alternativa em que constava nove planetas, ou seja, incluindo Plutão entre os planetas que compõem o sistema solar.

Nosso próximo objetivo era de verificar o conhecimento da turma sobre a posição dos planetas do sistema solar tomando como ponto de partida seu astro principal "O Sol". Mais que a metade da turma não detinha o conhecimento de qual, dentre os oito planetas do sistema solar, seria o mais próximo ao Sol. Acreditamos que devido ao fato de o planeta Marte estar em maior evidência, ou seja, ser referenciado com maior frequência em notícias e reportagens sobre astronomia, os alunos tenham assinalado essa alternativa.

\subsection{Análise das atividades em grupo}

As atividades foram aplicadas ao término de cada aula proposta.

\subsubsection{Atividade I - Representação do sistema solar}

Podemos perceber, ao observar os resultados do primeiro trabalho, ilustrado na figuras 4, que tinha como objetivo verificar o conhecimento dos estudantes acerca do tamanho dos planetas e da distância entre eles na composição do sistema solar, que os estudantes não representaram os planetas com as dimensões proporcionalmente corretas, percebemos que o planeta Saturno foi representado com dimensão menor que o planeta Terra, sendo que na realidade Saturno tem o diâmetro equatorial aproximadamente dez vezes maior que o planeta em que vivemos.

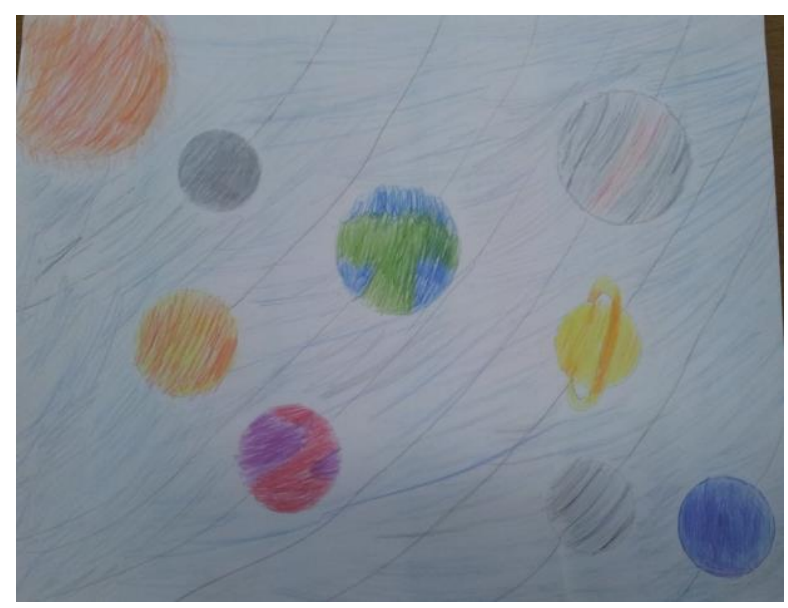

Figura 4. Representação do Sistema Solar 
V Congresso Brasileiro de Informática na Educação (CBIE 2016)

Anais do XXVII Simpósio Brasileiro de Informática na Educação (SBIE 2016)

Nos trabalhos apresentados os estudantes não consideraram a distância entre os planetas, ou seja, percebe-se que foram colocados à mesma distância. Sabe-se que há uma distância considerável entre os planetas e que pode ser representada através da proporcionalidade em um desenho.

\subsubsection{Atividade 2 - Representação do diâmetro dos planetas}

A figura 5 representa o segundo trabalho desenvolvido pelos estudantes ao término da segunda aula e tinha como objetivo verificar o aprendizado da turma referente a dimensão dos planetas. $\mathrm{O}$ trabalho apresentado nessa figura foi o que mais nos chamou atenção devido a criatividade dos estudantes e o cuidado com a representação das cores dos planetas, esse trabalho demonstra a aprendizagem dos alunos quanto a dimensão dos planetas e suas características.

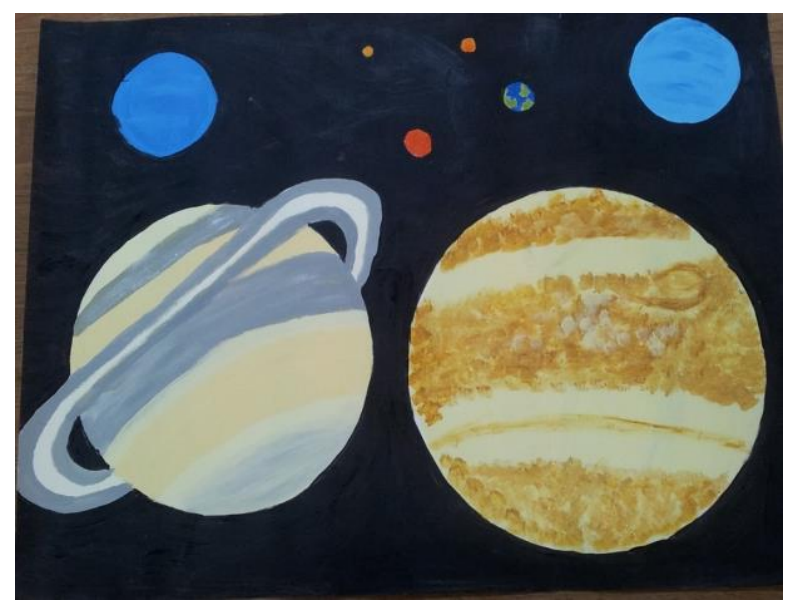

Figura 5. Representação do diâmetro dos planetas

\subsubsection{Atividade 3 - Representação da distância entre os planetas (extraclasse)}

A figura 6 está ilustrando a atividade desenvolvida fora da sala de aula, a qual os alunos deveriam representar o Sistema Solar. Cada aluno representaria um planeta e outro o Sol, além disso teriam que, através de uma escala elaborada por eles, representar a distância de cada planeta em relação ao Sol. Percebemos que essa atividade contribuiu muito para o aprendizado dos alunos, proporcionando um ambiente saudável de discussão referente ao conteúdo e a execução da atividade.

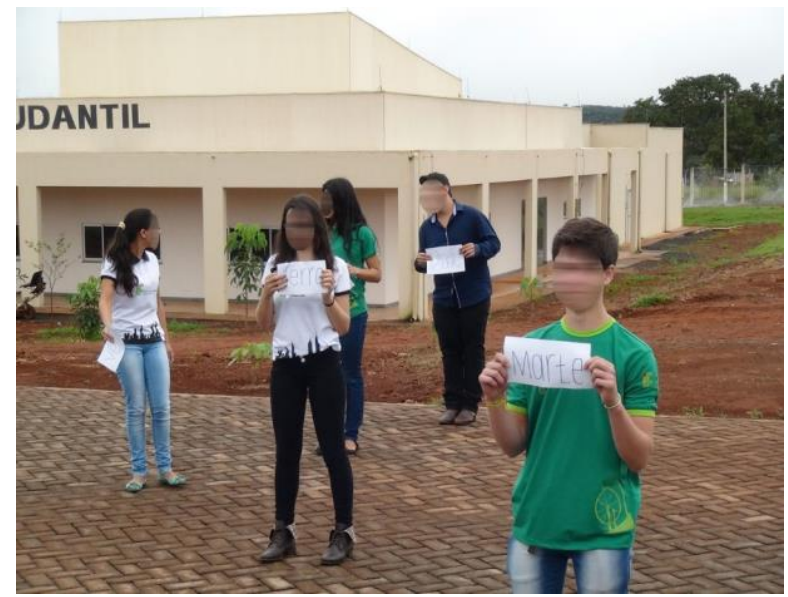


V Congresso Brasileiro de Informática na Educação (CBIE 2016)

Anais do XXVII Simpósio Brasileiro de Informática na Educação (SBIE 2016)

\section{Figura 6. Atividade em grupo}

\subsection{Análise do pós-teste}

Elaboramos o pós-teste utilizando as mesmas questões do teste diagnóstico, porém, com respostas abertas, ou seja, dissertativas. Sendo assim o estudante não teria as alternativas para o auxiliar nas respostas.

Com relação a quantidade de planetas existentes no sistema solar, qual o nome da maior estrela do sistema solar e qual o planeta que fica mais próximo ao Sol, obtivemos um resultado satisfatório, cem por cento dos estudantes responderam corretamente as questões. Acreditamos que isso se deve ao número de vezes que foi abordado esses conceitos durante as aulas e às atividades desenvolvidas em grupo.

Quando questionados sobre qual o maior planeta do sistema solar, ainda há uma pequena porcentagem dos estudantes que não responderam corretamente. Acreditamos que seja pelo fato de os dois maiores planetas do sistema solar, terem tamanhos relativamente próximos.

\subsection{Análise das percepções dos estudantes sobre a ferramenta com realidade aumentada}

O questionário sobre as percepções dos estudantes tinha como objetivo verificar como era a utilização da tecnologia por parte dos professores no desempenho de suas atividades didáticas, assim como verificar o conhecimento dos estudantes sobre $\mathrm{o}$ manuseio do computador e sobre o manuseio do software desenvolvido. Cem por cento da turma afirmou que na escola são desenvolvidas atividades de ensino na sala de informática e a maioria da turma avalia como positivo ou muito positivo, o uso do computador como auxilio ao entendimento das matérias vistas em sala de aula.

Além de concordarem de que, com a utilização do software desenvolvido nessa pesquisa, fica mais claro assimilar o conteúdo, os alunos apontaram que a sequência didática instiga os alunos a procurarem assuntos relacionados ao conteúdo estudado.

\section{Conclusão}

Ao finalizar este trabalho compreendemos que as Tecnologias de Informação e Comunicação (TIC) permitem criar ambientes que ampliam as possibilidades de formas de interação e intervenção no processo de ensino e de aprendizagem. Ao usar as TIC em sua prática pedagógica, o professor, tem em mãos uma alternativa que pode enriquecer suas aulas com utilização de vídeos, simuladores, aplicativos educacionais, entre outros. Por meio de programas governamentais, a maioria das escolas dispõe de alguns computadores conectados à Internet, porém poucas escolas conseguem reunir condições para manter um laboratório de ensino de Física.

Assim, nos parece que o investimento em recursos tecnológicos nas escolas é cada vez mais necessário nos dias atuais, pois nos aproxima do cotidiano da maioria dos estudantes. Compreendemos que os recursos digitais não substituem o uso de atividades práticas no ensino de ciências, porém pode auxiliar o professor, no espaço e tempo das escolas, a planejar melhor suas aulas com o crescente uso das tecnologias de informação e comunicação aplicada ao processo de ensino. 
V Congresso Brasileiro de Informática na Educação (CBIE 2016)

Anais do XXVII Simpósio Brasileiro de Informática na Educação (SBIE 2016)

A respeito do conhecimento adquirido pelos alunos acreditamos que houve uma maior aprendizagem do conteúdo trabalhado com eles, analisando as respostas fornecidas nos questionários e os debates ocorridos em sala de aula. Podemos perceber que um maior número de acertos das questões e um engajamento dos alunos na execução das atividades propostas, o que nos leva a crer que a sequência didática, produto principal desse estudo, teve boa aceitação e cumpriu seu objetivo.

Baseando-se nas análises das respostas fornecidas pelos estudantes aos questionários, e por meio dos debates ocorridos em sala de aula, podemos afirmar que houve uma aprendizagem do conteúdo trabalhado. Não podemos deixar de mencionar o fato ocorrido no primeiro dia da aplicação da sequência didática, onde assim que os alunos acessaram a aplicação ocorreu um problema que, somente um técnico em informática conseguiria solucionar. Sendo assim, consideramos de fundamental importância o planejamento e a preparação cuidadosa da atividade nos laboratórios de informática. Um profissional capacitado na área de informática para dar suporte ao professor quando ele optar pela utilização de TIC em suas aulas nos parece também um ponto importante para o sucesso das aulas nos laboratórios de informática.

\section{Referências}

Bardin, L.. Análise de conteúdo. São Paulo: Edições 70, 2004.

Cardoso, R. G. S. et al. Uso da realidade aumentada em auxílio à Educação. Anais do Computer on the Beach, p. p. 330-339, 2014.

Coll, C.; Monereo, C.. Psicologia da Educação Virtual: aprender e ensinar com as tecnologias da informação e da comunicação. Porto Alegre: Artmed, 2010.

Kirner, C.; Siscoutto, R.. Realidade virtual e aumentada: conceitos, projeto e aplicações. In: Livro do IX Symposium on Virtual and Augmented Reality, Petrópolis (RJ), Porto Alegre: SBC. 2007.

Moran, J. M.; Masetto, M. T.; Behrens, M. A. Novas tecnologias e mediação pedagógica. 10. ed. [S.1.: s.n.], 2006. 173 p.

Moreira, M. A.. Metodologias de pesquisa em ensino. São Paulo: Editora Livraria da Física, 2011.

Prezotto, E. D.; Silva, T. L. da, Vanzin, R.. Realidade aumentada aplicada a educação. Encontro Anual de Tecnologia da Informação. 2013 ano3 n1 p.322-326

Souza, R. C.; Kirner, C.. Ensino e Aprendizagem de Eletromagnetismo usando Recursos de Realidade Aumentada. RENOTE, v. 9, n. 1, 2011.

Vieira, Z. N. de L.. A informática na educação. Rio de Janeiro: Universidade Candido Mendes, 2006.

Zabala, A. A Prática Educativa: como ensinar. São Paulo: Artmed, 1998. 